\title{
Self-management for obesity and cardio-metabolic fitness: Description and evaluation of the lifestyle modification program of a randomised controlled trial
}

\author{
Tahna L Pettman*1,2, Gary MH Misan ${ }^{1,2}$, Katherine Owen ${ }^{1,3}$, Kate Warren², \\ Alison M Coates ${ }^{1}$, Jonathan D Buckley ${ }^{1}$ and Peter RC Howe ${ }^{1}$
}

Address: ${ }^{1}$ Australian Technology Network (ATN) Centre for Metabolic Fitness and Nutritional Physiology Research Centre, School of Health Sciences, University of South Australia, Adelaide 5000, South Australia, Australia, ${ }^{2}$ Spencer Gulf Rural Health School, c/o University of South Australia, Nicolson Avenue Whyalla 5608, South Australia, Australia and ${ }^{3}$ Centre for Health Economics Research and Evaluation (CHERE), University of Technology Sydney, Broadway 2007, UK

Email: Tahna L Pettman* - tahna.pettman@health.sa.gov.au; Gary MH Misan - gary.misan@unisa.edu.au; Katherine Owen - katherine.owen@uts.edu.au; Kate Warren - kate.warren@unisa.edu.au; Alison M Coates - alison.coates@unisa.edu.au; Jonathan D Buckley - jon.buckley@unisa.edu.au; Peter RC Howe - peter.howe@unisa.edu.au

* Corresponding author

Published: 27 October 2008

International Journal of Behavioral Nutrition and Physical Activity 2008, 5:53 doi:10.1 I86/1479-5868-5-53

This article is available from: http://www.ijbnpa.org/content/5/I/53

(C) 2008 Pettman et al; licensee BioMed Central Ltd.

This is an Open Access article distributed under the terms of the Creative Commons Attribution License (http://creativecommons.org/licenses/by/2.0), which permits unrestricted use, distribution, and reproduction in any medium, provided the original work is properly cited.

\begin{abstract}
Background: Sustainable lifestyle modification strategies are needed to address obesity and cardiovascular risk factors. Intensive, individualised programs have been successful, but are limited by time and resources. We have formulated a group-based lifestyle education program based upon national diet and physical activity (PA) recommendations to manage obesity and cardio-metabolic risk factors. This article describes the content and delivery of this program, with information on compliance and acceptability.
\end{abstract}

Methods: Overweight/obese adults $(n=153)$ with metabolic syndrome were recruited from the community and randomly allocated to intervention (INT) or control (CON). Written copies of Australian national dietary and PA guidelines were provided to all participants. INT took part in a 16-week lifestyle program which provided a curriculum and practical strategies on I) dietary and PA information based on national guidelines, 2) behavioural self-management tools, 3) food-label reading, supermarkets tour and cooking, 4) exercise sessions, and 5) peer-group support. Compliance was assessed using attendance records and weekly food/PA logs. Participants' motivations, perceived benefits and goals were assessed through facilitated discussion. Program acceptability feedback was collected through structured focus groups.

Results: Although completion of weekly food/PA records was poor, attendance at information/ education sessions ( $77 \%$ overall) and exercise participation ( $66 \%$ overall) was high, and compared with CON, multiple markers of body composition and cardio-metabolic health improved in INT. Participants reported that the most useful program components included food-label reading, cooking sessions, and learning new and different physical exercises, including home-based options. Participants also reported finding self-management techniques helpful, namely problem solving and short-term goal setting. The use of a group setting and supportive 'peer' leaders were found to be supportive. More frequent clinical assessment was suggested for future programs. 


\begin{abstract}
Conclusion: This group-based lifestyle program achieved improvements in body composition and cardio-metabolic and physical fitness similar to individualised interventions which are more resource intensive to deliver. It confirmed that active training in lifestyle modification is more effective than passive provision of guidelines. Such programs should include social support and selfmanagement techniques. Continued clinical follow up may be required for long-term maintenance in individuals attempting lifestyle behaviour change. Program facilitation by peers may help and should be further investigated in a community-based model.
\end{abstract}

\section{Background}

A randomised, controlled, parallel group intervention trial aimed at improving body composition and cardiometabolic risk factors was conducted in free-living adults with metabolic syndrome (MetS). The study used a groupbased lifestyle modification program of non-energy restricted diet and physical activity (PA) intervention, based on the Australian national guidelines for diet and physical activity (PA). The intervention involved 103 participants and resulted in improvements in body composition, blood pressure, blood lipid levels, physical fitness and dietary intake, the details of which have been described elsewhere [1]. The purpose of this article is to provide a detailed description of the intervention used in the study, and to report on the acceptability of the program and the practical implications of applying national recommendations for lifestyle change.

\section{Rationale}

Obesity continues to be a major public health issue, and central obesity and MetS are also becoming increasingly prevalent. In Australia, approximately $60 \%$ of the population are overweight or obese [2], and 30\% have central obesity. Increasing levels of obesity, in particular central obesity, are also driving an increase in the prevalence of MetS [3]. Consensus on the long-term effectiveness of intervention programs for reducing obesity has not been established [4]. Similarly, there is no one agreed treatment for MetS [5]. Despite this, lifestyle intervention (weight loss, dietary improvement and PA) is emphasised as firstline therapy for these conditions. National guidelines for appropriate diet and PA are available, but the uptake of these recommendations is unknown.

Current literature suggests that significant effort is required to achieve sustained changes in body composition and metabolic health. Lifestyle intervention combining intensive dietary modification with prescribed levels of PA can reduce the incidence of chronic disease [6,7] but a range of factors can negatively influence the successful adoption and maintenance of positive lifestyle changes [8], resulting in difficulty improving lifestyle behaviours. Consequently, many programs demonstrate short term weight loss, for example at 3-6 months, but few show success in maintaining weight loss at 12 months or beyond
[9-11] Sustained weight loss and modification of risk factors has been achieved following long-term intensive interventions $[7,12]$ but these methods generally rely on prescribed diet and exercise together with counselling and supervision by dietitians, counsellors, physical trainers, psychologists and behaviourists. The use of highly prescriptive diet and exercise regimes may present difficulties for some people to integrate into their existing lifestyle, and the use of health professionals to work one-on-one with individuals in order to effectively implement this type of program can make such approaches cost and time intensive, and potentially unsustainable at the community level. Evaluations of primary-care based programs and applications of national lifestyle guidelines appear to be practical [13-17], and recent evidence suggests that they may be effective [18-20] but again these types of programs rely heavily on individualised intervention, making their delivery expensive.

The approach we are evaluating in this study involves a program conducted in a group setting, incorporating some of the potentially beneficial aspects of self-management programs (SMP). SMP appear to be effective for chronic disease management [21-23] and might also be useful for the prevention of chronic disease [24-26]. Key features of such programs include shared goal-setting, lifestyle skills teaching, ongoing follow-up and support [27] as well as promoting the establishment of peer support networks, which have been suggested as a useful tool for improving compliance with interventions for weight loss [28] and diabetes prevention [29]. Delivery of this program in a group setting rather than on an individual basis was aimed at reducing the resources required for the delivery of the program.

\section{Methods Clinical study design}

Volunteers were recruited from Whyalla, a regional community of South Australia with rates of overweight and obesity which exceed the State average. Adults in the community responded to media advertisements calling for volunteers to participate in the Shape up for Life lifestyle intervention trial which was aimed at changing lifestyle habit to reduce obesity and improve health. Beginning in 2006, 153 volunteers meeting international criteria [30] 
for MetS were enrolled (111 females, 42 males; aged 45.1 \pm 0.8 years). Participants weighed on average at baseline $102.6 \pm 2.3 \mathrm{~kg}$, and mean BMI was $36.6 \pm 0.7$. Mean waist circumference was $115 \pm 1 \mathrm{~cm}$. Individuals taking medication for blood pressure, blood lipids or with a diagnosis of diabetes mellitus (type 1 or type 2 ) were excluded. Eligible participants were randomly allocated to intervention (INT; $n=103$ ); or control (CON; $n=50)$. There were no significant differences in baseline characteristics between INT and CON. Assessments of anthropometry, body composition, cardiovascular and metabolic health, physical fitness, dietary intake, PA and quality of life were performed at baseline and after 4 and 12 months. The clinical study protocol was approved by the Human Research Ethics Committee of the University of South Australia, and all study participants provided written informed consent prior to participation.

\section{Lifestyle intervention}

All participants were provided with standard booklets of the Australian guidelines for healthy eating [31] and PA [32]. No other intervention was provided to CON. A structured 16 week information and education program and group exercise was conducted for INT. The program, called 'Shape up for Life', ran as group sessions for 2 hours each week.

\section{Key features of the program}

The program sessions were framed to translate the various recommendations and advice contained in National guideline documents into 'real life'. Practical strategies were used to aid in the uptake of dietary and physical activity recommendations, given that people are concurrently managing family, work and study; may have limited finances; may be travelling away from home frequently, and may work long and irregular hours (eg. split shifts and night shifts). Sessions were held at different times of the day/night and on different days/nights of the week, to accommodate participants' family and work commitments.

\section{Dietary and physical activity information}

Dietary topics covered during information/education sessions are summarised in Table 1. Information for these sessions was drawn from several resources including the Australian Guide to Healthy Eating [33] (AGHE), Nutrition Australia 'Healthy living book'[34] and factsheets [35] and Glycemic index (GI) Australian resources [33]. Dietary advice reflected what is advocated by the Australian dietary guidelines (ADG)[36], including advice to balance energy intake (ad libitum) with energy expenditure through daily activity. Participants were not given meal plans or individualised diet counselling, and energy tar-

Table I: Activities in the Shape up for Life program

\begin{tabular}{|c|c|}
\hline Dietary topic & Activity description \\
\hline Healthy eating \& Energy Balance & $\begin{array}{l}\text { Introduction to healthy eating - variety, quality; Balancing energy intake with expenditure; Energy and } \\
\text { Nutrient density of food; Barriers to eating healthily (food triggers), problem solve common issues }\end{array}$ \\
\hline Glycemic index (GI) & Background; Using Gl for choosing better quality $\mathrm{CHO}$; Reducing refined $\mathrm{CHO}$ \\
\hline Food labels & $\begin{array}{l}\text { Judging food quality; Identifying low fat/low sugar options based upon I) nutrition info panel 2) ingredients list } \\
\text { 3) nutrition claims }\end{array}$ \\
\hline Fats & $\begin{array}{l}\text { Recommended saturated fat intake; Types of fat; Choosing better quality fats, Benefits of omega-3 } \\
\text { polyunsaturated fatty acids and plant sterols }\end{array}$ \\
\hline Carbohydrate \& Fibre & Benefits of fibre; Disadvantages of low $\mathrm{CHO} /$ low fibre intake; Increasing fibre \\
\hline Salt & $\begin{array}{l}\text { Disadvantages of salt; Recommended sodium intake; Food sources; Brainstorm alternatives for flavouring } \\
\text { food without salt }\end{array}$ \\
\hline Shopping tips & Healthy eating on a budget \\
\hline Refresher: GI, Fat \& Salt & $\begin{array}{l}\text { Recap and feedback on Gl/CHO-Fat-Salt; What barriers participants have found, problem-solve common } \\
\text { issues }\end{array}$ \\
\hline Food variety & Importance of variety; Food variety checklist (Nutrition Australia fact sheet) \\
\hline Takeaway food & Disadvantages of excess takeaway; Brainstorm alternatives \\
\hline Alcohol \& Caffeine & Disadvantages of excess alcohol \& caffeine; Brainstorm alternatives \\
\hline Supermarket 'secrets' & Judging quality, price and processing of food \\
\hline Physical activity topic & Activity description \\
\hline Exercise \& Energy Balance & Introduction to exercise - Endurance, Resistance, Flexibility; Using pedometer and physical activity diary \\
\hline Endurance exercise I & $\begin{array}{l}\text { Moderate intensity exercise; FIT formula } \\
\text { (Frequency, Intensity, Time); monitoring exercise intensity (Talk-test, RPE, HR) }\end{array}$ \\
\hline Resistance training I & Benefits of strength training; Common questions; Using resistance bands \\
\hline Flexibility exercise & Importance of stretching; How to stretch safely and effectively \\
\hline Endurance exercise2 & $\begin{array}{l}\text { Recap and Feedback on exercise; Increasing variety by adding to FITI formula (Frequency, Intensity, Time, } \\
\text { and Type) }\end{array}$ \\
\hline Resistance training2 & Benefits of building lean tissue; How to lift safely and effectively \\
\hline
\end{tabular}


gets were not prescribed. Specific macronutrient and micronutrient requirements were not discussed, except for general recommendations to reduce saturated fat, sodium and alcohol (consistent with ADG). Rather, quality and variety of dietary intake were emphasised. Emphasis was placed upon improving dietary quality through the intake of more nutrient dense foods (that are inherently less energy dense), replacing refined carbohydrates with low GI and fibre-rich options, replacing sources of saturated fats with polyunsaturated fats, reducing salt/sodium intake, and increasing food variety from recommended food groups (mainly vegetables, fruits, grains, nuts and seeds). Participants were encouraged to moderate their intake of alcohol and caffeine, and to drink more water. Health benefits of the standard dietary recommendations were also discussed, including the use of lower GI foods for regulation of blood glucose and satiety; and omega-3 fats for cardiovascular benefit and body fat reduction [37]. Some of the practical issues regarding food choices were also discussed, including shopping on a budget, incorporating meat alternatives (if desired), modifying recipes to make healthier meals, trying new foods on family/children, and choosing more appropriate 'fast food' options.

PA topics are summarised in Table 1. Information regarding physical activity and exercise was drawn from several resources, including National PA guidelines, Active Australia 'getting started' booklet [38], Council on the Ageing (COTA) factsheets (accessed online http://www.cota.org.au), and State government of Victoria consumer health fact sheets (accessed online http://www.goforyourlife.vic.gov.au/). Participants were not given specific targets other than to aim to achieve the PA recommendations of the national guidelines. Education topics included: why exercise is important; differentiation between the benefits of different types of exercise (cardiovascular, resistance, flexibility); benefits of moderate intensity aerobic activity; monitoring exercise intensity; using the FITT principle (Frequency, Intensity, Time, Type) to vary and increase activity; and the importance of incidental and transport-related activity. Options for incorporating resistance training into an exercise regimen were also discussed (and demonstrated), including the use of resistance bands, own body weight, dumbbells, bar-bells and resistance machines, highlighting the benefit of improving body composition through increasing lean tissue (fat-free) mass. Participants in INT were provided with free access to a gymnasium during the intervention period to assist with the adoption of exercise guidelines.

\section{Behavioural lifestyle self-management}

Lifestyle self-management tools used in the intervention are summarised in Table 2. We encouraged the use of strategies to address some of the barriers to adopting healthy lifestyle habits, achieved mainly by incorporating tools adapted from the Stanford chronic disease SMP, originally developed by Lorig and colleagues [39]. One of the essential features that we incorporated was short-term goal setting, or 'action planning', as described by the Stanford model, which teaches participants to break long term goals into smaller, more achievable (action-specific) steps. 'Triggers' affecting food and PA choices were discussed, using an activity adapted from the DPP Lifestyle balance core program, entitled "take charge of what's around you" [40]. Another activity called 'obesity prevention', which was inspired by concepts introduced by Swinburn and Egger [41], was used to raise awareness of external/environmental obesity-promoting factors (eg. technology, convenience food, limited fresh food access).

Another concept that was introduced and referred to throughout the program was a diagrammatic concept of the 'vicious cycle' (Figure 1) in overweight/obesity, which was based upon the 'symptom cycle' described in the Stanford chronic disease SMP. This was intended to illustrate both the negative and positive impact that people can have on their own health behaviour and weight (body fat) management. In the chronic disease context, the cycle is used to highlight that symptoms experienced are not due to only one cause (the disease) but interactions of various other symptoms (for example; stress can cause tense muscles which may cause pain). For our purpose, factors that can contribute to weight (body fat) gain were included, and self-management strategies to address these issues were highlighted. For example; it was suggested that fatigue/tiredness can reduce motivation for exercise, which can lead to loss of fitness and de-conditioning, potentially increasing risk of pain and injury when exercising, and negatively self-perpetuating the 'cycle'. It was also posed that secondary behaviours may arise from an existing issue or problem; for example fatigue/tiredness/ stress may lead to non-hungry eating or poor food choices (e.g. energy-dense snacks or fast food). The alternative focus of the cycle we proposed was that healthy behaviours can have a positive impact on other lifestyle factors, for example; managing sore joints through appropriate exercise can increase flexibility and improve ability, which can boost motivation for PA and in turn impact positively upon other issues through positive feedback. Further description on the adaptation of self-management activities from the Stanford course may be found elsewhere [42].

\section{Food labels, shopping and cooking}

To demonstrate 'real-life' dietary and activity changes, practical activities were conducted. These practical activities included food-label reading education using real product labels, and referring participants to Nutrition Australia recommendations for understanding food labels $[34,43]$. Participants were encouraged to bring in labels from their own shopping to discuss. A visit to a local 
Table 2: Lifestyle self-management tools used in Shape up for Life

\begin{tabular}{|c|c|c|c|}
\hline Activity title & Delivery method & Description & Anticipated outcomes \\
\hline $\begin{array}{l}\text { Action Planning, Problem } \\
\text { solving }\end{array}$ & $\begin{array}{l}\text { Leader facilitates sharing of } \\
\text { information }\end{array}$ & $\begin{array}{l}\text { Behaviour-specific short goal } \\
\text { setting, addressing lifestyle barriers }\end{array}$ & $\begin{array}{l}\text { Learn to set reasonable, } \\
\text { behaviour-specific goals (shared or } \\
\text { individual), and monitor personal } \\
\text { goals/progress }\end{array}$ \\
\hline $\begin{array}{l}\text { Managing food and activity } \\
\text { triggers }\end{array}$ & $\begin{array}{l}\text { Group brainstorm, problem } \\
\text { solving }\end{array}$ & $\begin{array}{l}\text { Identify habits relating to diet and } \\
\text { physical activity, selecting common } \\
\text { issues to address. }\end{array}$ & $\begin{array}{l}\text { Learn coping strategies for } \\
\text { personal dietary issues (eg. } \\
\text { snacking), and for increasing } \\
\text { opportunities for physical activity }\end{array}$ \\
\hline $\begin{array}{l}\text { Managing family, social and } \\
\text { cultural pressures }\end{array}$ & $\begin{array}{l}\text { Group brainstorm, problem } \\
\text { solving }\end{array}$ & $\begin{array}{l}\text { Identify habits associated with } \\
\text { social situations and cultural/family } \\
\text { habits, selecting common issues to } \\
\text { address }\end{array}$ & $\begin{array}{l}\text { Learn coping strategies for habitual } \\
\text { overeating and drinking, and for } \\
\text { increasing opportunities for } \\
\text { physical activity }\end{array}$ \\
\hline Progressive muscle relaxation & $\begin{array}{l}\text { Leader reads and directs scripted } \\
\text { activity }\end{array}$ & $\begin{array}{l}\text { Guided practice of relaxation of } \\
\text { major muscle groups }\end{array}$ & $\begin{array}{l}\text { Raise body/muscle awareness to } \\
\text { assist in movement patterns (eg. } \\
\text { for exercise), and general tension } \\
\text { release }\end{array}$ \\
\hline Better breathing & $\begin{array}{l}\text { Leader provides lecturette \& reads } \\
\text { script for activity }\end{array}$ & $\begin{array}{l}\text { Guided practice of breathing fully } \\
\text { and more effectively }\end{array}$ & $\begin{array}{l}\text { Learn to breathe diaphragmatically, } \\
\text { to assist in physical activity, and for } \\
\text { relieving shortness of breath, and } \\
\text { general tension }\end{array}$ \\
\hline Fatigue management & $\begin{array}{l}\text { Leader provides lecturette, group } \\
\text { brainstorm }\end{array}$ & $\begin{array}{l}\text { Identify causes of, and solutions } \\
\text { for, managing fatigue }\end{array}$ & $\begin{array}{l}\text { Learn coping strategies to address } \\
\text { low energy, to improve } \\
\text { motivation; in general and for } \\
\text { physical activity }\end{array}$ \\
\hline Self talk (positive thinking) & $\begin{array}{l}\text { Leader provides lecturette, group } \\
\text { brainstorm }\end{array}$ & $\begin{array}{l}\text { Identify personal negative } \\
\text { thoughts, and how to change into } \\
\text { positive, constructive thought } \\
\text { patterns }\end{array}$ & $\begin{array}{l}\text { Learn to use helpful thoughts for } \\
\text { motivation, improve self-efficacy to } \\
\text { reach goals }\end{array}$ \\
\hline Depression management & $\begin{array}{l}\text { Leader provides lecturette, group } \\
\text { brainstorm }\end{array}$ & $\begin{array}{l}\text { Identify causes of, and suggestions } \\
\text { for managing difficult times in life }\end{array}$ & $\begin{array}{l}\text { Learn coping strategies to assist in } \\
\text { managing for motivation, improve } \\
\text { self-efficacy to achieve and } \\
\text { maintain lifestyle changes }\end{array}$ \\
\hline $\begin{array}{l}\text { Mind management and } \\
\text { distraction }\end{array}$ & $\begin{array}{l}\text { Leader provides lecturette \& reads } \\
\text { script for activity }\end{array}$ & $\begin{array}{l}\text { Guided practice of cognitive short- } \\
\text { term distraction techniques }\end{array}$ & $\begin{array}{l}\text { Learn to use distracting thoughts } \\
\text { to assist in managing behavioural } \\
\text { issues, self-control, (eg. for eating } \\
\text { and physical activity) and stress }\end{array}$ \\
\hline $\begin{array}{l}\text { Making informed treatment } \\
\text { decisions }\end{array}$ & $\begin{array}{l}\text { Leader provides lecturette, group } \\
\text { brainstorm }\end{array}$ & $\begin{array}{l}\text { Discussion about health } \\
\text { treatments (eg. weight loss } \\
\text { products and programs) } \\
\text { highlighting possible benefits, risks } \\
\text { and efficacy }\end{array}$ & $\begin{array}{l}\text { Raise overall awareness of issues } \\
\text { relating to health-related } \\
\text { treatments, highlighting need to } \\
\text { make informed decisions about } \\
\text { lifestyle choices }\end{array}$ \\
\hline Guided imagery & Leader reads script for activity & $\begin{array}{l}\text { Guided practice of cognitive } \\
\text { relaxation sequence }\end{array}$ & $\begin{array}{l}\text { Learn to use relaxing thoughts to } \\
\text { assist in relaxation, relieve stress } \\
\text { and tension }\end{array}$ \\
\hline Obesity prevention & $\begin{array}{l}\text { Leader provides lecturette, group } \\
\text { brainstorm }\end{array}$ & $\begin{array}{l}\text { Discussion of hosts, carriers and } \\
\text { environments contributing to } \\
\text { obesity, suggestions for change }\end{array}$ & $\begin{array}{l}\text { Raise overall awareness of the } \\
\text { modifiable social, environmental } \\
\text { and individual influences on } \\
\text { lifestyle }\end{array}$ \\
\hline
\end{tabular}

supermarket provided participants with another opportunity to review nutrient information labels, nutrient claims, and to physically compare different food products to determine which were better quality. In these interactive tours, participants were directed towards buying seasonal produce and alternatives such as frozen vegetables, dried beans, and tinned fruit. Participants were directed to judge for themselves the nutritional value of commonlyused products such as bakery and delicatessen items, savoury crackers, margarines and spreads, yoghurts and dairy desserts. Two interactive cooking sessions were conducted to demonstrate meal ideas consistent with education topics, and to encourage variation in the intake of foods, condiments and cooking methods. During these sessions participants were provided with recipes and ingredients to prepare various meals, snacks and desserts. A cookbook was later compiled and provided to participants, including the recipes individuals contributed during sessions. 


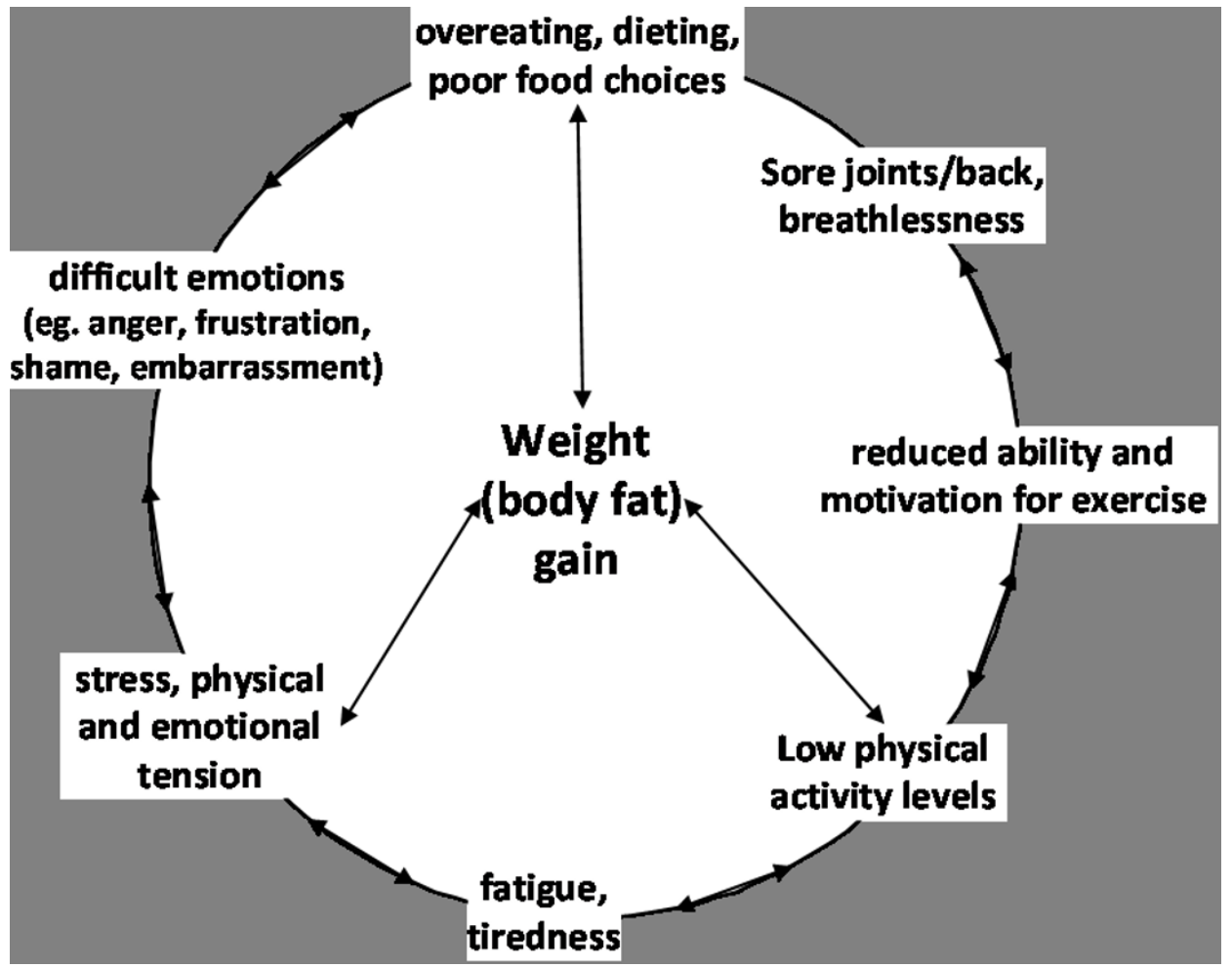

Figure I

Diagrammatic representation of the 'vicious cycle' used throughout the Shape up for Life program.

\section{Exercise sessions}

Participants were asked to attend at least one supervised exercise session each week during the intervention period. Group exercise was conducted for 45-60 minutes, usually directly after the information session. Additional sessions were held at different times to accommodate participants' work/family commitments. Study leaders demonstrated techniques such as heart-rate monitoring for aerobic activity, safe and effective use of gym equipment, core strengthening, and stretches. Examples of other types of exercises included in the sessions were walk-aerobics [44], weightroom circuits, aerobics, step/dance-aerobics, handweights and resistance bands, mixed circuits, and Tai Chi. Gymnasium facilities were established at the commencement of the study, shared with University staff and students, equipped with resistance and cardio machines, dumbbells, fitballs, boxing bags, mats and space for aerobics (with a TV and CD/DVD players). These facilities were made freely available to participants after they had been instructed in their correct use by study staff. Rubber resistance bands and handouts on exercise examples were offered for home use. Pedometers (step-counters) were also provided to encourage participants to monitor their movement through daily incidental activity. Participants were informed that a recommended level to work towards achieving was 10,000 steps per day, which appears to be in line with national recommendations [45-47]. Heart rate monitors were available during exercise sessions to encourage participants to monitor their cardiovascular exercise intensity.

\section{Peer-group setting}

Information sessions were presented by two leaders, and groups consisted of up to fifteen individuals per session. Several repeat sessions were held throughout the week to accommodate all participants. The intervention was conducted by a study coordinator with health science/nutrition background together with a leader with expertise and experience in chronic disease SMP facilitation and training. Both leaders assumed a 'peer' role in conducting sessions, in that they provided information for participants to consider incorporating into their existing lifestyles. Leaders encouraged all participants to modify their own dietary and PA behaviours. Participants were also encouraged to share their experiences and ideas, to listen to and be respectful of others in the group, and to interact with each other both during and outside of sessions. 


\section{Additional program materials}

The lifestyle program was compiled as a "leader's manual" which included written narratives, brainstorming activities, and prompts for leaders to 'model' lifestyle behaviours. PowerPoint ${ }^{\mathrm{TM}}$ slides were designed and used to guide session conduct. The manual ensured session consistency for the different intakes of study participants, and also served as a 'script', so that with training, individuals other than study coordinators would be able to lead future education sessions. Other supporting materials for the program included action-plan templates, a weekly food and PA record, information hand-outs, study newsletters, recipes and fact-sheets.

\section{Compliance assessments}

Weekly attendance was recorded for each individual, for attendance at both information and PA sessions. If absent from information sessions, participants were followed up by phone to ascertain a reason and to schedule a 'catch up' prior to the next week's session, and were encouraged to do their own exercise if they were unable to attend group exercise (or did not wish to take part in group exercise). Sample foods were provided by sponsor companies to offer to participants as examples of healthy products (wholegrain breads, breakfast cereal, tinned fish and unsalted nuts). A template log was provided to participants to complete during the week to record their PA together with the number of serves of food products consumed.

\section{Participant feedback}

Individuals' motivations for wanting to achieve lifestyle changes, and their perceptions of how much their lifestyle had changed were discussed during the information session at week 12. Questions were intended to prompt reflection on healthy habits adopted as a result of the program (being 3 months into the intervention), and also to focus on maintaining these changes (having only 1 month until the end of the intervention when physical assessments would be performed). Participants were asked why they were taking part in the study; and what changes they had made as a result. Participants' personal goals were collected at the end of the intervention at session week 16. Long-term goal-setting was conducted to encourage behaviour maintenance over the remaining 8 months of the study. Participant responses were transcribed verbatim and later categorised into common themes. Finally, feedback was invited from study participants after the 16-week program. Focus groups were conducted by researchers who were independent from the delivery of the study, with the aim of evaluating participants' satisfaction with the program. Examples of information gathered included (1) participants' opinions on the diet and PA components of the program, (2) how the program impacted on the participants/their families, (3) whether participation enabled sustainable lifestyle changes, and (4) suggestions for improvement of the program.

\section{Data analysis}

Data were collated and analysed using MS Excel (Microsoft corporation, US) and SPSS 15.0 for Windows (SPSS Inc, Chicago, Illinois). Session attendance counts and weekly report completion scores were entered into spreadsheets and chi-square analyses were performed. Correlations (Spearman) were performed using SPSS. Data from weekly records (i.e. number of food serves; duration of PA) were not directly used, due to overall poor completion. However, the records received were assessed for completeness, and these scores were incorporated into the overall compliance assessment. Qualitative data (participant quotes) were transcribed verbatim and entered into spreadsheets, and subjective responses were reduced and grouped thematically to reveal predominant themes. Focus group data were recorded on audiotape, transcribed, and compiled thematically using evaluative codes.

\section{Results \\ Clinical outcomes}

The success of the clinical study has been described elsewhere [1]. The study demonstrated that the intervention was effective in improving body composition (4\% reduction in body fat mass and abdominal body fat mass, $3 \mathrm{~cm}$ waist reduction), blood pressure ( $>5 \%$ reduction), total cholesterol and LDL ( 8 - 10\% reduction), and physical fitness (12\% improvement). There were also statistically significant correlations within-individuals between attendance at program sessions and clinical changes from baseline. For example, greater attendance at information and exercise sessions was associated with greater reductions in body fat (Figure 2), blood pressure (DBP $r=-0.31$, $p<0.001$; and SBP $r=-0.28, p=0.01)$, total cholesterol $(r$ $=-0.35, p<0.001)$ and plasma glucose $(r=-0.35, p<$ $0.001)$. Dietary intake and PA outcomes were limited by the methods of data collection; however both groups (intervention and control) significantly reduced overall energy intake and increased levels of PA (data not shown).

\section{Program compliance}

Information session attendance was $77 \%$, with an average of 12 sessions attended out of a total of 15 or 16 scheduled (one program intake was condensed into 15 sessions due to the course overlapping Christmas). Exercise sessions were less attended at $66 \%$ overall, with an average of 9 sessions attended out of a possible 14 conducted (two sessions were not followed by exercise due to time constraints (cooking)). In most cases, the reasons for nonattendance to information/exercise sessions were related to work or family commitments (data not shown). 

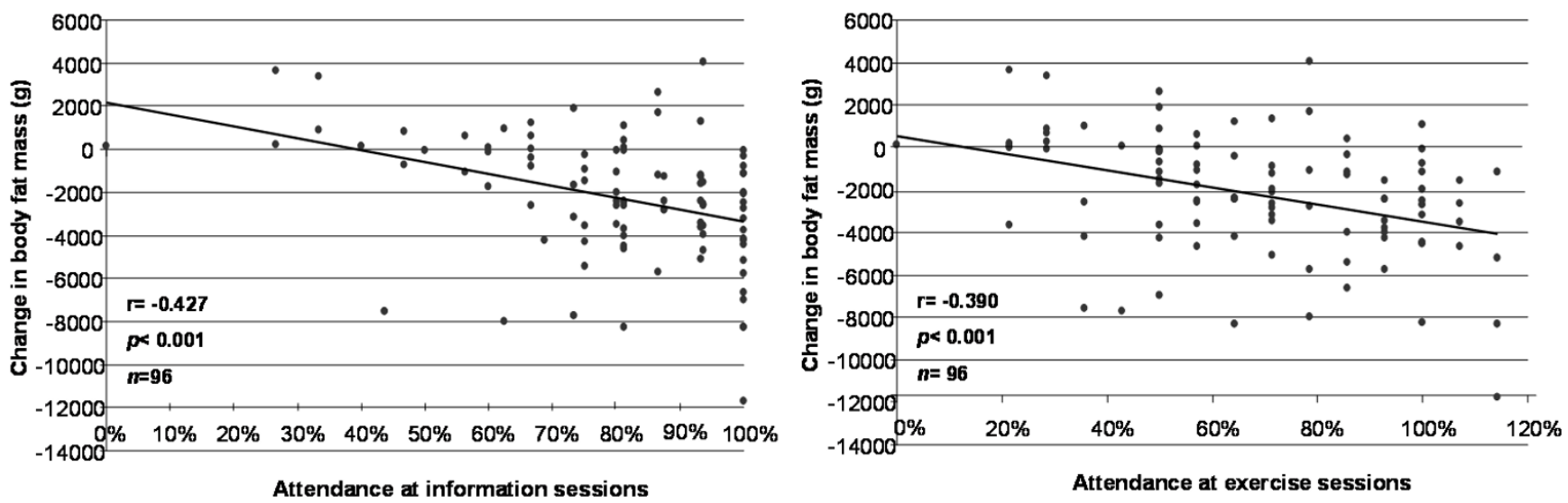

Figure 2

Correlations between rate of attendance at intervention program sessions and reduction in body fat mass. Note: Attendance at exercise exceeded $100 \%$ in some cases as participants chose to attend more sessions than required.

Attendance declined gradually approximately half-way through the program (Figure 3 ). Based upon data from other interventions $[15,48-50]$ and testing with chisquare; attendance to information sessions did not differ from an expected $75 \%(p=$ NS) but exercise sessions were in fact attended more than an expected $50 \%(p<0.001)$.

Weekly participant diet and physical activity records were poorly maintained, with approximately one-third of the group not completing or not returning weekly records, and another third did not complete fully or accurately. Ultimately a subjective assessment was made by two research staff (one of whom was actively engaged in the program with the participants, and another who had no direct contact with participants) to judge the accuracy of returned records. A score was allocated by mutual agreement between the two research staff, of $0=$ effectively non-compliant; $0.5=$ uncertain or partly-compliant (eg. not attending exercise sessions, but reported doing additional PA outside of sessions); or $1.0=$ appears compliant.

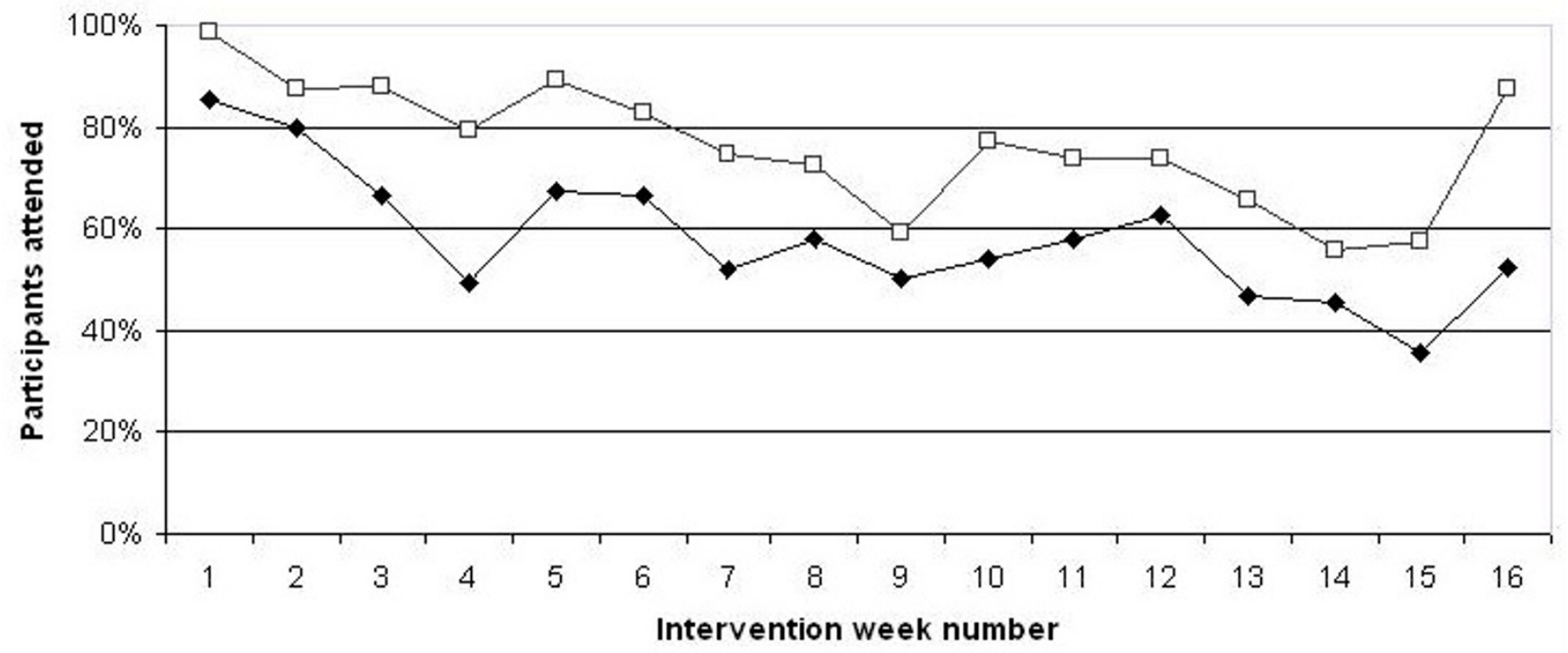

$\rightarrow$ Full compliance - attendance to both info + exercise sessions

$\rightarrow-$ Info compliance - attendance to information only

Figure 3

Attendance at intervention sessions (all participants, $n=103$ ). 
The average of all scores was 0.51 (part-compliant). Attendance at exercise sessions were significantly correlated with attendance at information sessions. Weekly report completion scores also correlated significantly with information session attendance (Table 3 ).

\section{Participant perceptions}

A total of $n=124$ responses were obtained from the group sessions (week 12 and week 16) where questions were posed (Figure 4). Reasons for taking part in the program $(n=33)$ were predominantly to reduce risk for diabetes, metabolic or cardiovascular disease (25\%); to change lifestyle or habits (18\%); and to lose weight or look better $(15 \%)$. Other categories that emerged included improve quality of life; improve mindset/thinking; improve general health; eat healthier; and get fitter. Discussion of lifestyle habits changed elicited themes such as eating breakfast; healthier/less snacks or better food choices overall; drinking more water and/or less alcohol and caffeine; improved cooking and less takeaway purchase; inclusion of more fish, nuts, fruit, veg and wholegrains; more self-discipline, self control, motivation and better habits; making informed choices and reading food labels; more exercise and/or resistance exercise; and reduced fat/ saturated fat, sugar and salt. The categories with the greatest responses were reduced fat/saturated fat, sugar and salt (22\%) and more exercise and/or resistance exercise $(17 \%)$. Personal goals made $(n=32)$ when prompted to consider making a goal at the end of the program included firstly to lose 2 dress/trouser sizes or $5 \mathrm{~kg}(24 \%)$; to maintain lifestyle changes (18\%) and to lose 10-15 kg (18\%).

\section{Program acceptability}

Finally, feedback from study participants during focus groups was used evaluate overall satisfaction with the program. A total of 33 participants volunteered to take part in these focus groups. Questions and guided discussion revealed information on 3 common areas; food/dietary factors, exercise issues, and support. Participants reported that food-label reading and information on takeaway food were useful, together with cooking sessions. Participants were pleased that the program leaders took a peer role in all sessions, and had realistic expectations of them, particularly in exercise sessions. Home-based exercise options were viewed favourably; however participants reported needing follow-up instructions, such as use of resistance bands. Provision of the gym was appreciated (due to cost saved), but for many it was not utilised with the main reason reported for this lack of use being embarrassment.

Regarding overall program structure, participants felt that the leaders' encouraging attitudes assisted with compliance, and found goal-setting and problem solving skills useful. Home-based exercise options, monthly study newsletters, and importantly the commonalities amongst the peer group were also appreciated and considered to be useful. The group setting was found to be of a supportive nature, and new social supports were formed as a result.

A common suggestion made was to schedule more frequent clinical assessments, to maintain motivation and be aware of personal progress. It was suggested that this take place half-way through the intervention (week 8). Participants reported having experienced a feeling of loss at the end of the intervention. Some participants suggested that future programs include a referral pathway (e.g. to counsellor or psychologist) to deal with underlying issues causing barriers to behaviour change.

\section{Discussion}

The intervention program evaluated in the current analysis was effective in improving a range of health outcomes in INT compared to CON and that are described elsewhere [1]. Despite an average of approximately two thirds of sessions attended overall, this was sufficient to improve diet, increase PA and produce clinically relevant outcomes in free-living individuals with MetS. This suggests that the methods and delivery of this program were acceptable.

Table 3: Correlation coefficients for attendance at sessions and compliance outcomes (Spearman) all participants $(n=103)$

\begin{tabular}{|c|c|c|c|c|c|}
\hline & $\begin{array}{c}\text { Exercise } \\
\text { attendance }\end{array}$ & $\begin{array}{l}\text { Information } \\
\text { attendance }\end{array}$ & $\begin{array}{l}\text { Weekly log } \\
\text { completion score }\end{array}$ & $\begin{array}{l}\text { Overall compliance } \\
\text { score }\end{array}$ & $\begin{array}{l}\text { Non-compliance } \\
\text { score }\end{array}$ \\
\hline $\begin{array}{l}\text { Exercise } \\
\text { attendance }\end{array}$ & $(1.00)$ & $0.80 * *$ & $0.63 * *$ & $0.86 * *$ & $-0.82 * *$ \\
\hline $\begin{array}{l}\text { Information } \\
\text { attendance }\end{array}$ & $0.80 * *$ & $(1.00)$ & $0.68 * *$ & $0.87 * *$ & $-0.99 * *$ \\
\hline $\begin{array}{l}\text { Weekly reports } \\
\text { completion score }\end{array}$ & $0.63^{* *}$ & $0.68^{* *}$ & $(1.00)$ & $0.91 * *$ & $-0.68 * *$ \\
\hline $\begin{array}{l}\text { Overall compliance } \\
\text { score }\end{array}$ & $0.86^{* *}$ & $0.87^{* *}$ & $0.91 * *$ & $(1.00)$ & $-0.87^{* *}$ \\
\hline $\begin{array}{l}\text { Non compliance } \\
\text { score }\end{array}$ & $-0.82 * *$ & $-0.99 * *$ & $-0.68^{* *}$ & $-0.87^{* *}$ & $(1.00)$ \\
\hline
\end{tabular}

** Correlation is significant at the 0.01 level (2-tailed). 
Panel A. Participants' perceived lifestyle changes made ( $n=124$ responses)

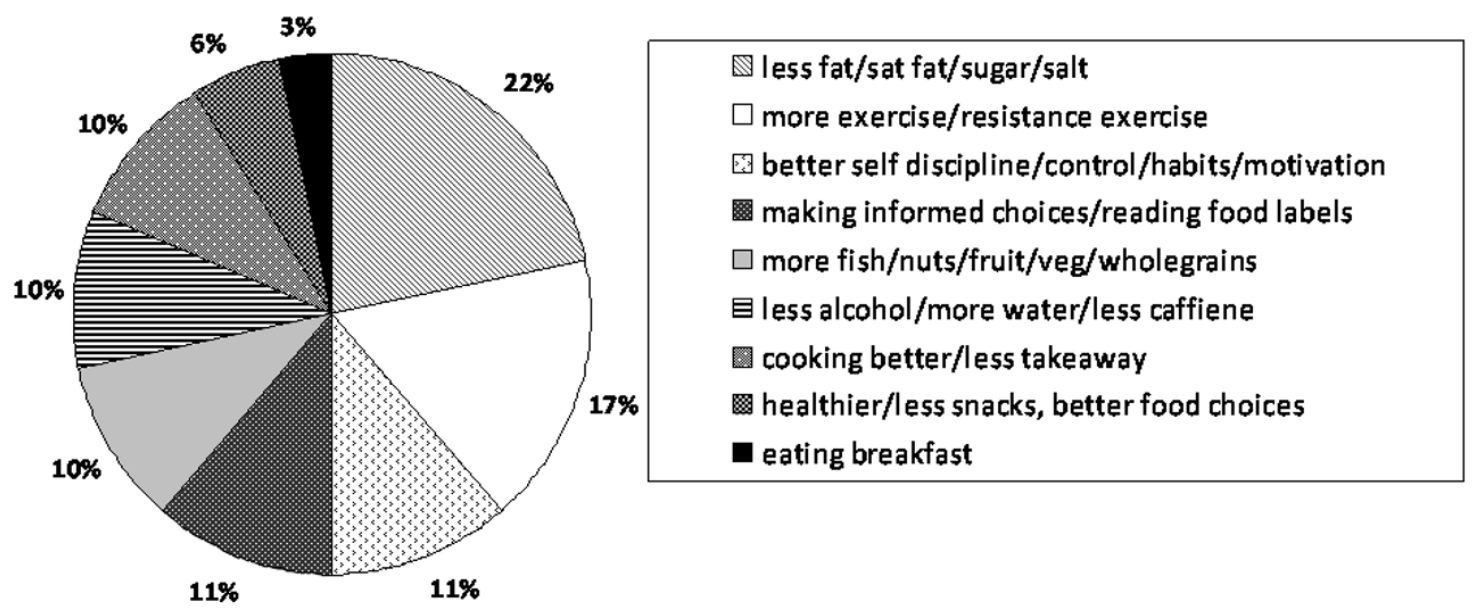

Panel B. Participants' reasons for taking part in lifestyle change program ( $n=33$ responses)

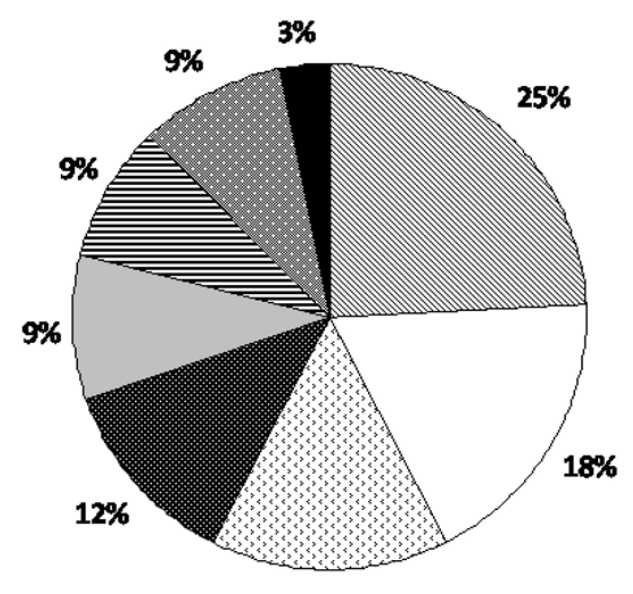

\begin{tabular}{|l}
$\mathbb{Q}$ reduce risk factors (metabolic/cardiovascular/diabetes) \\
$\square$ change habits or lifestyle \\
lose weight/look better \\
improve quality of life \\
$\square$ eat healthier \\
O improve health \\
$\square$ improve mindset/thinking \\
$\square$ get fitter
\end{tabular}

$15 \%$

Panel C. Participants' 'long-term goals' made at end of program ( $n=32$ responses)

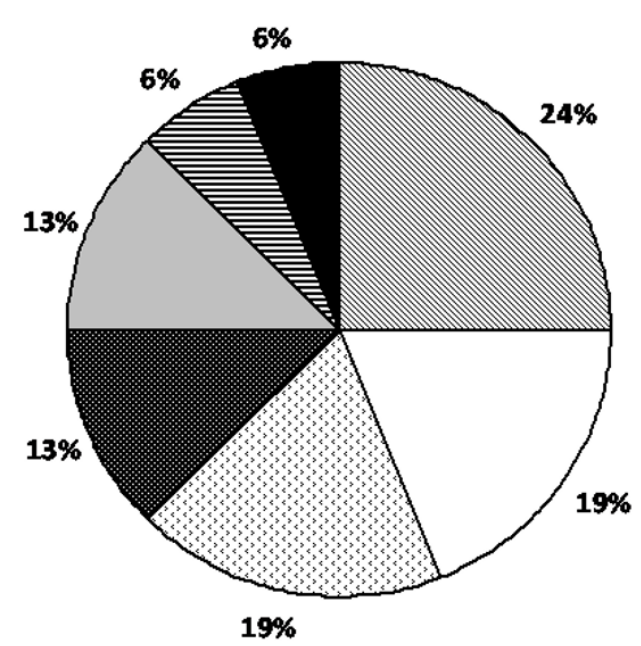

$\mathbb{Q}$ lose 2 dress/trouser sizes/ $5 \mathrm{~kg}$

$\square$ lose $10-15 \mathrm{~kg}$

[0] maintain lifestyle changes

圈 increase fitness/ exercise

$\square$ reduce size/waist (not specific)

目 look better (eg. in swimwear)

reduce body fat/weight (not specific)

Figure 4

Participant responses during facilitated discussion. 
Also, the content and structure of the program has to some extent been reported as acceptable by participants.

\section{Program content}

The content of the education program was based upon Australian national guidelines. There is recent evidence to suggest that lifestyle intervention in accordance with general lifestyle recommendations can be beneficial to health in at-risk individuals $[15,18,20]$ when delivered by health professionals/lifestyle counsellors. In order to achieve clinically significant outcomes through our group-based approach, we hypothesised that promoting dietary quality would result in a more balanced, nutrient-dense diet, with increased complex carbohydrate, bioactive nutrient and fibre intake, together with reduced total energy intake. Additionally we hypothesised that benefit may be gained by introducing participants to the 'functional' aspects of recommended foods (low GI, omega-3), for which the evidence-base relating to health benefits is increasing [5154]. Our intervention program provided a simple, groupbased approach to improving diet and PA, and essentially provided a strategy for encouraging adoption of the national recommendations. Consequently this intervention may be more easily transferred into communities than complicated or restrictive diets and personalised or prescribed exercise, which are generally unsustainable.

The overall aim of the PA component of the intervention was to increase energy expenditure and promote overall fitness by increasing moderate/vigorous exercise and incidental/low intensity (long-duration) leisure activity in accordance with national guidelines. We encouraged engagement in regular PA in order to achieve not only body fat reduction, but also to improve risk factors which constitute the metabolic syndrome. [55,56]

We also proposed that self-management techniques, that have proven successful in the management of chronic disease, might also be applicable in managing overweight $[26,57]$. Lifestyle topics and strategies were incorporated to address some of the external and personal issues that are often barriers to healthy lifestyle choices. The activities incorporated were adapted from other successful SMP's described previously. The effectiveness of the Stanford techniques for chronic disease have been demonstrated internationally $[21,58]$ and locally [59].

The literature suggests that programs combining diet, exercise, and behaviour modification are the most effective for improving health outcomes in the short term [60] (as cited in [61]). Self-managed strategies are also useful in the management of weight [26] and are considered to apply especially well to preventive interventions involving lifestyle modification [57]. In our program, practical sessions and supervised exercise were included to address 'real-life' aspects of dietary choice and PA, and to introduce participants to different options to consider. Selfefficacy is also recognised as associated with health behaviour change [62] and current evidence continues to confirm it's importance to diet and activity [63]. Therefore action planning and problem solving were integral to the program to promote self-efficacy; through accomplishing small, weekly behavioural goals which would lead to achieving a larger health-related goal.

\section{Program format and conduct}

Recent data has indicated that group-based lifestyle intervention with monthly follow-up can improve body weight, PA, health and wellbeing to a similar extent as individualised dietetic treatment. [64] In our program, group meetings were conducted for all sessions. A group setting was used to more effectively manage a number of individuals over time, compared one-on-one individual interventions [64]. A similar strategy has also been recently described for engaging larger groups of individuals; through adaptation of the DPP intervention for delivery in the community [17]. Additionally there is evidence to show that the social support network may assist individuals in maintaining weight loss through continued follow-up [28], shared short-term goal setting and problem solving [26], which is also why we considered the peergroup setting to be a useful strategy. The presence of a peer leader endeavouring to achieve the same lifestyle goals as the other participants also provided a source of collegial support.

\section{Program duration and follow-up}

Based upon published outcomes of the American and Finnish Diabetes prevention studies [7,65], and other trials conducted in our research clinic [66] we considered that a 4 month period was sufficient to demonstrate the effect of the intervention on study outcome measures. In order to maximise the potential benefit of the intervention, but without over-burdening participants, education meetings were scheduled weekly for 1 hour with 45-60 min exercise following. Frequency of contact was adapted from the 'Lifestyle balance' program by the Diabetes Prevention Program Research Group (DPPRG)[40], the aims of which were weight loss and increased PA. Weekly contact in initial stages is accepted as standard for weight loss interventions [67]. These and other reports suggest that individuals are more likely to maintain lifestyle changes if they have regular follow-up [28]. [67-70]

\section{Program compliance}

Assessments of compliance revealed that the program was well tolerated. The gradual decline in attendance appearing approximately half-way through may suggest 'program fatigue', but no further data is available to support this. Interventions of longer duration tend to have greater 
attrition [48] and more than 50\% dropout might be expected in community-based interventions [19]. Although commitment to weekly sessions may have been at times difficult to manage for participants, it appears that these compliance rates are acceptable. To compare with other lifestyle interventions [15,48-50], we might expect average attendance of $75 \%$ to information, and $50 \%$ to exercise sessions, so attendance to our information sessions was consistent with other studies, and exercise adherence slightly better. Attendance to information tended to predict attendance to group exercise, which may indicate that the format of the program was useful in encouraging participation in exercise, as participants may have been more likely to join in group exercise or use the gym (directly after the information session). Some have suggested the use of home-based exercise equipment as a means to improving adherence in overweight adults, especially women [71] which appears to be consistent with the feedback reported by participants during focus groups. Some research indicates that although home-based training is not as effective at improving factors such as glycemic control, it is effective for maintaining improvements in muscle strength and lean body mass following gymnasium-based training [72].

Compliance with self-reports were poorly completed, with only one-third of participants returning a reasonable record of weekly PA and food serves consumed. Adherence to self-monitoring during lifestyle intervention is a complex issue and is notoriously sub-optimal [73], which is consistent with other weight-management studies $[12,74]$.

\section{Program uptake/acceptability}

Our understanding of participants' perceived lifestyle changes and reasons for being involved is limited to a small sample of responses. Despite this, some common themes were identified that appear to support the major aims of the program but this may be biased due to the most motivated individuals attending focus groups, and also because responses were collected during the intervention. For perceived lifestyle changes, most frequent responses were around specific dietary changes, and engagement in formal exercise (including resistance exercise and trying new activities) and incidental PA. Other interesting comments included feelings of self-discipline, self control, motivation and the formation of better habits. Although it is difficult to extrapolate from this small sample of responses, it appeared that the main motivations given for participating were not simply to 'lose weight', but to modify size, health risk factors and lifestyle habits. This may be suggesting that individuals taking on lifestyle changes were seeing a bigger picture than actually making dietary and activity adjustments.

\section{Mechanisms}

Results from the focus-group indicated that there was significant value in certain aspects of the dietary education provided, including food-label reading, cooking, and nutritional composition of packaged foods. There was also interest in specific information on serving sizes and daily allowances, which may have benefitted the more motivated individuals to better understand their required energy intake. Participants also suggested more instruction for home-based exercises. Participants considered peer-leadership to be important and interactive sessions more valuable than a didactic format, and the peer-group setting was important for collegial support. Learning and applying self-management skills was also found to be useful. Clinical monitoring, progress checks and continued support were also identified as vital for continued motivation. The acknowledgement of psychological counselling is not a surprising finding owing to the complex nature of obesity and the underlying issues that present barriers to healthy lifestyle.

Participants commented that the session content was appropriate to the level of understanding of the participants, and participants consequently were empowered to make behavioural changes. Increased feelings of wellbeing and achievement were noted as a result. It was identified that there is a need to focus on maintenance and support of these behaviours after the cessation of the intervention, including clinical assessment and social support networks.

\section{A simpler strategy for lifestyle modification?}

Community or population level interventions need to be simple and inexpensive to be cost effective. The Ottawa charter for health promotion (WHO) states that healthy choices should be the easy choices [75] and there is further evidence emerging that this may empower individuals to continue making the healthy choices [76]. This is an important consideration in this context, where the ultimate goal is to avoid preventable lifestyle disease. This study was predicated on the assumption that the usual dietary restriction and high levels of PA to counter overweight are difficult for the general population to sustain [77]. Our approach was to implement a program based on dietary and PA guidelines that were already in place, and to assess its effect on clinical outcomes in comparison to a control group who were simply provided with the guideline documents.

This study also confirms that simply providing written guidelines to CON was not sufficient to effect significant change in dietary and physical activity behaviour. The implication of this is that the current practice of government and other organisations to develop and disseminate written guidelines will not of itself address the needs of 
overweight individuals. Rather these guidelines are best accompanied by additional support strategies including active behavioural intervention and practical examples that translate guidelines into everyday strategies that assist individuals from different backgrounds in achieving lifestyle recommendations

To our knowledge, this is the first demonstration of a targeted self-management program for individuals who are overweight/obese with MetS, in a randomised controlled trial. Longer-term research is warranted to understand whether a peer-led model would translate into improvements in body composition, cardiovascular risk factors and quality of life, and whether it would be readily accepted in the community. The current intervention has achieved success in the short-term, and analysis of long term clinical and compliance data will contribute to current understandings of the effectiveness of 'modest' lifestyle intervention on body composition and metabolic fitness. The importance of active or follow-up in maintaining improvements will be of particular interest in this assessment. Further research may then be warranted to investigate the sustainability of a similar program in a peer led, community-based setting.

\section{Competing interests}

The authors declare that they have no competing interests.

\section{Authors' contributions}

All authors read, assisted in editing and approved the final manuscript. TLP drafted the manuscript, coordinated the design and conduct of the clinical study, co-created the intervention program, and conducted the intervention. GMHM was project manager, was involved conducting the intervention, and contributed to drafting and revising the manuscript. KO assisted in drafting and revision of the manuscript. KW assisted in coordination and conduct of the clinical study, co-created the intervention program, and conducted the intervention. AMC contributed to the clinical study design and drafting of the manuscript. JDB contributed to the clinical study design and revision of the manuscript. PRCH contributed to the clinical study design and revision of the manuscript

\section{Acknowledgements}

We thank Debra Misan for assistance in study coordination and program delivery, and all the study participants in Whyalla - without their commitment this work would not have been possible. Project funding was received from the ATN Centre for Metabolic Fitness and Spencer Gulf Rural Health School (SGRHS), with additional support from the University of South Australia Whyalla campus (Centre for Regional Engagement) and SGRHS.

\section{References}

I. Pettman TL, Misan GMH, Coates AM, Buckley JD, Howe PRC: Shape up for Life: a community-based diet and lifestyle program for metabolic syndrome. Asia Pacific Journal of Clinical Nutrition 2007, 16(Suppl 3):S44.
2. Australian Bureau of Statistics: National Health Survey: Summary of Results 2004-05. Commonwealth of Australia 2006.

3. Cameron AJ, Magliano DJ, Zimmet PZ, Welborn T, Shaw JE: The Metabolic Syndrome in Australia: Prevalence using four definitions. Diabetes Research and Clinical Practice 2007, 77(3):47I-478.

4. Hill J, Thompson H, Wyatt H: Weight Maintenance: What's Missing? Supplement to J Am Diet Assoc 2005, I05:S63-S66.

5. International Diabetes Federation: A new worldwide definition of the metabolic syndrome - Consensus from the International Diabetes Federation could help stop the cardiovascular disease time bomb Berlin, 14 April 2005. 2005.

6. Laaksonen DE, Lakka H-M, Salonen IT, Niskanen LK, Rauramaa R, Lakka TA: Low Levels of Leisure-Time Physical Activity and Cardiorespiratory Fitness Predict Development of the Metabolic Syndrome. Diabetes Care 2002, 25(9):1612-1618.

7. Tuomilehto J, Lindstrom J, Eriksson JG, Valle TT, Hamalainen H, llanne-Parikka P, Keinanen-Kiukaanniemi S, Laakso M, Louheranta A, Rastas M, et al.: Prevention of Type 2 Diabetes Mellitus by Changes in Lifestyle among Subjects with Impaired Glucose Tolerance. N Engl J Med 200I, 344( I 8): I343-I 350.

8. Wing RR, Hill JO: Successful weight loss maintenance. Annual Review of Nutrition 200I, 2 I(I):323-34I.

9. Noakes M, Keogh JB, Foster PR, Clifton PM: Effect of an energyrestricted, high-protein, low-fat diet relative to a conventional high-carbohydrate, low-fat diet on weight loss, body composition, nutritional status, and markers of cardiovascular health in obese women. Am J Clin Nutr 2005, 8 I (6): I 298- I 306.

10. Ebbeling CB, Leidig MM, Feldman HA, Lovesky MM, Ludwig DS: Effects of a Low-Glycemic Load vs Low-Fat Diet in Obese Young Adults: A Randomized Trial. JAMA 2007, 297(19):2092-2102.

II. Stern L, Iqbal N, Seshadri P, Chicano KL, Daily DA, McGrory J, Williams M, Gracely EJ, Samaha FF: The Effects of Low-Carbohydrate versus Conventional Weight Loss Diets in Severely Obese Adults: One-Year Follow-up of a Randomized Trial. Ann Intern Med 2004, I 40( I0):778-785.

12. The Diabetes Prevention Program Research Group: Achieving Weight and Activity Goals Among Diabetes Prevention Program Lifestyle Participants. Obesity Res 2004, I 2(9): I 426- I 434.

13. Wolf AM, Conaway MR, Crowther JQ, Hazen KY, L Nadler J, Oneida $B$, Bovbjerg VE: Translating Lifestyle Intervention to Practice in Obese Patients With Type 2 Diabetes: Improving Control with Activity and Nutrition (ICAN) study. Diabetes Care 2004, 27(7): $1570-1576$.

14. Martin PD, Rhode PC, Dutton GR, Redmann SM, Ryan DH, Brantley PJ: A Primary Care Weight Management Intervention for Low-Income African-American Women. Obesity 2006, 14:1412-1420.

15. Kilkkinen A, Heistaro S, Laatikainen T, Janus E, Chapman A, Absetz P, Dunbar J: Prevention of type 2 diabetes in a primary health care setting: Interim results from the Greater Green Triangle (GGT) Diabetes Prevention Project. Diabetes Research and Clinical Practice 2007, 76(3):460-462.

16. Vale M, Jelinek M, Best J: Impact of coaching patients on coronary risk factors - Lessons from the COACH Program. Disease Management \& Health Outcomes 2005, I 3(4):225-244.

17. Ackermann RT, Marrero DG: Adapting the Diabetes Prevention Program Lifestyle Intervention for Delivery in the Community: The YMCA Model. The Diabetes Educator 2007, 33(I):69-78.

18. Mensink M, Blaak EE, Corpeleijn E, Saris WH, de Bruin TW, Feskens E): Lifestyle Intervention According to General Recommendations Improves Glucose Tolerance. Obesity Res 2003, II(I2):1588-1596.

19. Graffagnino CL, Falko JM, Londe ML, Schaumburg J, Hyek MF, Shaffer LET, Snow R, Caulin-Glaser T: Effect of a Community-Based Weight Management Program on Weight Loss and Cardiovascular Disease Risk Factors. Obesity 2006, 14:280-288.

20. Absetz P, Valve R, Oldenburg B, Heinonen H, Nissinen A, Fogelholm M, Ilvesmaki V, Talja M, Uutela A: Diabetes Care 2007:dc07-017I.

21. Lorig K, Ritter P, Stewart A, Sobel D, Brown W, Bandura A, Gonzalez $V$, Laurent D, Holman H: Chronic Disease Self-Management Program: 2-Year Health Status and Health Care Utilization Outcomes. Medical Care 200 I, 39(I I): I I I - I 223.

22. Lorig K, Sobel D, Ritter P, Laurent D, Hobbs M: Effect of a SelfManagement Program on Patients with Chronic Disease. Effective Clinical Practice 200I, 4(6):256-262. 
23. Norris SL, Engelgau MM, Venkat Narayan KM: Effectiveness of Self-Management Training in Type 2 Diabetes: A systematic review of randomized controlled trials. Diabetes Care 200I, 24(3):56|-587.

24. Tang TS, Gillard ML, Funnell MM, Nwankwo R, Parker E, Spurlock D, Anderson RM: Developing a New Generation of Ongoing Diabetes Self-management Support Interventions: A Preliminary Report. The Diabetes Educator 2005, 3 I (I):91-97.

25. Uutela A, Absetz P, Nissinen A, Valve R, Talja M, Fogelholm M: Health Psychological Theory in Promoting Population Health in Päijät-Häme, Finland: First Steps toward a Type 2 Diabetes Prevention Study. I Health Psychol 2004, 9(I):73-84.

26. The Counterweight project team: A new evidence-based model for weight management in primary care: the Counterweight Programme. J Hum Nutr Dietet 2004, 17: 19|-208.

27. Fisher EB, Brownson CA, O'Toole ML, Shetty G, Anwuri VV, Fazzone P, Housemann RA, Hampton AD, Kamerow DB, McCormack LA, et al.: The Robert Wood Johnson Foundation Diabetes Initiative: Demonstration Projects Emphasizing Self-management. The Diabetes Educator 2007, 33(I):83-94.

28. Wing RR, Jeffery RW: Benefits of recruiting participants with friends and increasing social support for weight loss and maintenance. Journal of Consulting and Clinical Psychology 1999, 67(1):132-138.

29. Lindstrom J, Louheranta A, Mannelin M, Rastas M, Salminen V, Eriksson J, Uusitupa M, Tuomilehto J: The Finnish Diabetes Prevention Study (DPS): Lifestyle intervention and 3-year results on diet and physical activity. Diabetes Care 2003, 26(I 2):3230-3236.

30. International Diabetes Federation: The IDF consensus worldwide definition of the metabolic syndrome. Brussels: International Diabetes Federation; 2005.

31. The Children's Health Development Foundation: The Australian Guide to Healthy Eating. Ageing DoHa: Commonwealth of Australia; 1998.

32. An active way to better health. National Physical Activity Guidelines for Australian adults. Department of Health and Ageing: Commonwealth of Australia; 1999.

33. The Glycemic Index: The Official Website of the Glycemic Index and GI Database [http://www.glycemicindex.com/]

34. Nutrition Australia: the Healthy Living Book Melbourne: The Australian Nutrition Foundation Inc; 2005.

35. Food Fact Sheets [http://www.nutritionaustralia.org/Food Facts/ Fact Sheets/fact sheets index.asp]

36. National Health and Medical Research Council: Dietary Guidelines for Australian Adults Commonwealth of Australia; 2003.

37. Hill AM, Buckley JD, Murphy KJ, Howe PRC: Combining fish-oil supplements with regular aerobic exercise improves body composition and cardiovascular disease risk factors. Am J Clin Nutr 2007, 85(5): 1 267-1274.

38. Active Australia: Everyone wants to be more active. The problem is getting started Department of Health and Ageing and Sports Medicine Australia.

39. Lorig K: Living Improvements For Everyone: A course in Chronic Disease Self-Management CA USA: Stanford Patient Education Research Centre, Leland Stanford Junior University; 1999.

40. The Diabetes Prevention Program Lifestyle Resource Core: Lifestyle Balance: Healthy eating - being active University of Pittsburgh; 1996.

4I. Swinburn B, Egger G: The runaway weight gain train: too many accelerators, not enough brakes. BMJ 2004, 329:736-739.

42. Warren K, Pettman Tahna L, Misan D, Misan G: Does Chronic Disease Self-Management (CDSM) have a role in preventing chronic disease in rural Australia? In 9th National Rural Health Conference: 2007; Albury, NSW Australia National Rural Health Alliance; 2007.

43. Nutrition Australia: Food fact sheet - Demystifying food labels.

44. Sansome Leslie: Advanced Walkaerobics. Newark, NJ, USA: Parade Video; 1989

45. Hultquist CN, Albright C, Thompson DL: Comparison of Walking Recommendations in Previously Inactive Women. Med Sci Sports Exerc 2005, 37(4):676-683.

46. Tudor-Locke C, Bassett DR Jr: How Many Steps/Day Are Enough? Preliminary Pedometer Indices for Public Health. Sports Med 2004, 34(I): I-8.
47. McCormack G, Giles-Corti B, Milligan R: Demographic and individual correlates of achieving 10,000 steps/day: use of pedometers in a population-based study. Health Promotion Journal of Australia 2006, I 7(I):43-47.

48. van Gool CH, Penninx BWJH, Kempen GIJM, Miller GD, van Eijk JTM, Pahor M, Messier SP: Determinants of high and low attendance to diet and exercise interventions among overweight and obese older adults - Results from the arthritis, diet, and activity promotion trial. Contemporary Clinical Trials 2005, 27:227-237.

49. Carroll S, Borkoles E, Polman R: Short-term effects of a non-dieting lifestyle intervention program on weight management, fitness, metabolic risk, and psychological well-being in obese premenopausal females with the metabolic syndrome. Applied Physiology Nutrition and Metabolism 2007, 32(I): 125.

50. Catenacci VA, Wyatt HR: The role of physical activity in producing and maintaining weight loss. Nature clinical practice Endocrinology \& Metabolism 2007, 3(7):5|8-529.

51. Coates AM, Howe PC: Edible nuts and metabolic health. Curr Opin Lipidol 2007, I 8( I 8):25-30.

52. Ebbeling C, Leidig M, Sinclair K, Seger-Shippee L, Feldman H, Ludwig D: Effects of an ad libitum low-glycemic load diet on cardiovascular disease risk factors in obese young adults. Am J Clin Nutr 2005, 81:976-982.

53. Heilbronn LK, Noakes M, Clifton PM: The Effect of High- and Low-Glycemic Index Energy Restricted Diets on Plasma Lipid and Glucose Profiles in Type 2 Diabetic Subjects with Varying Glycemic Control. J Am Coll Nutr 2002, 2I(2): I20-I27.

54. Kris-Etherton PM, Harris WS, Appel LJ, for the Nutrition C: Fish Consumption, Fish Oil, Omega-3 Fatty Acids, and Cardiovascular Disease. Circulation 2002, I 06(2I):2747-2757.

55. Lee S, Kuk JL, Katzmarzyk PT, Blair SN, Church TS, Ross R: Cardiorespiratory Fitness Attenuates Metabolic Risk Independent of Abdominal Subcutaneous and Visceral Fat in Men. Diabetes Care 2005, 28(4):895-90।

56. Katzmarzyk PT, Church TS, Janssen I, Ross R, Blair SN: Metabolic Syndrome, Obesity, and Mortality: Impact of cardiorespiratory fitness. Diabetes Care 2005, 28(2):391-397.

57. Glasgow RE, Orleans CT, Wagner EH, Curry SJ, Solberg LI: Does the Chronic Care Model Serve Also as a Template for Improving Prevention? The Milbank Quarterly 200I, 79(4):579-6I2.

58. Lorig KR, Sobel DS, Ritter PL, Laurent D, Hobbs M: Effect of a SelfManagement Program on Patients with Chronic Disease. Effective Clinical Practice 200I, 4(6):256-262.

59. Department of Health and Ageing: National Evaluation of the Sharing Health Care Initiative. Ageing DoHa: Australian Government; 2005.

60. National Institutes of Health: Clinical Guidelines on the Identification, Evaluation, and Treatment of Overweight and Obesity in Adults - The Evidence Report. Obes Res 1998, 6 Suppl 2:5IS-209S.

6I. Wing RR, Goldstein MG, Acton KJ, Birch LL, Jakicic JM, Sallis JF Jr, Smith-West D, Jeffery RW, Surwit RS: Behavioral Science Research in Diabetes: Lifestyle changes related to obesity, eating behavior, and physical activity. Diabetes Care 200I, 24(1): 117-123.

62. Strecher VJ, McEvoy DeVellis B, Becker MH, Rosenstock IM: The Role of Self-Efficacy in Achieving Health Behavior Change. Health Educ Behav 1986, I3(I):73-92.

63. Burke V, Beilin LJ, Cutt HE, Mansour J, Mori TA: Moderators and mediators of behaviour change in a lifestyle program for treated hypertensives: a randomized controlled trial (ADAPT). Health Educ Res 2008, 23(4):583-59I.

64. Ash S, Reeves M, Bauer J, Dover T, Vivanti A, Leong C, O'Moore Sullivan T, Capra S: A randomised control trial comparing lifestyle groups, individual counselling and written information in the management of weight and health outcomes over 12 months. Int J Obes 2006, 30( I 0): 1557-1564.

65. Diabetes Prevention Program Research Group: Reduction in the Incidence of Type 2 Diabetes with Lifestyle Intervention or Metformin. N Engl J Med 2002, 346(6):393-403.

66. Hill AM, Buckley JD, Murphy KJ, Howe PC: Combining fish-oil supplements with regular aerobic exercise improves body composition and cardiovascular disease risk factors. Am J Clin Nutr 2007, 85(5): I 267-I 274. 
67. Perri MG, Nezu AM, Patti ET, McCann KL: Effect of length of treatment on weight loss. Journal of Consulting and Clinical Psychology 1989, 57(3):450-452.

68. Renjilian DA, Perri MG, Nezu AM, McKelvey WF, Shermer RL, Anton SD: Individual versus group therapy for obesity: Effects of matching participants to their treatment preferences. Journal of Consulting and Clinical Psychology 200I, 69(4):7I7-72I.

69. Perri MG, Nezu AM, McKelvey WF, Shermer RL, Renjilian DA, Viegener B]: Relapse prevention training and problem-solving therapy in the long-term management of obesity. Journal of Consulting and Clinical Psychology 2001, 69(4):722-726.

70. The Diabetes Prevention Program Research Group: The Diabetes Prevention Program (DPP): Description of lifestyle intervention. Diabetes Care 2002, 25(I 2):2165-2 I7I.

7I. Jakicic JM, Winters C, Lang W, Wing RR: Effects of Intermittent Exercise and Use of Home Exercise Equipment on Adherence, Weight Loss, and Fitness in Overweight Women: A Randomized Trial. JAMA 1999, 282(16): I554- I560.

72. Dunstan DW, Daly RM, Owen N, Jolley D, Vulikh E, Shaw J, Zimmet P: Home-Based Resistance Training Is Not Sufficient to Maintain Improved Glycemic Control Following Supervised Training in Older Individuals With Type 2 Diabetes. Diabetes Care 2005, 28(I):3-9.

73. Burke LE, Sereika S, Choo J, Warziski M, Music E, Styn M, Novak J, Stone A: Ancillary study to the PREFER trial: A descriptive study of participants' patterns of self-monitoring - rationale, design and preliminary experiences. Contemporary Clinical Trials 2006, 27(I):23-33.

74. Butryn ML, Phelan S, Hill JO, Wing RR: Consistent Self-monitoring of Weight: A Key Component of Successful Weight Loss Maintenance. Obesity 2007, I 5( I 2):309|-3096.

75. Ottawa charter for health promotion [http://www.who.int/ hpr/NPH/docs/ottawa charter hp.pdf]

76. Koelen MA, Lindstrom B: Making healthy choices easy choices: the role of empowerment. Eur J Clin Nutr 2005, 59 Suppl $\mathrm{I}:$ SIO-SI5.

77. Buckley JD, Hill AM, Coates AM, Howe PRC: Simpler diet and exercise strategies for managing obesity. In Physical activity and obesity Edited by: Hills AP, King NA, Byrne NM. Smith-Gordon and Nishimura; 2006:100-104.

Publish with Bio Med Central and every scientist can read your work free of charge

"BioMed Central will be the most significant development for disseminating the results of biomedical research in our lifetime. "

Sir Paul Nurse, Cancer Research UK

Your research papers will be:

- available free of charge to the entire biomedical community

- peer reviewed and published immediately upon acceptance

- cited in PubMed and archived on PubMed Central

- yours - you keep the copyright
BioMedcentral 